\title{
La desinformación en el actual contexto informativo. El caso de la pandemia del COVID-19
}

\author{
Disinformation in the Current Informative Context. \\ The Case of the Pandemic
}

Recepción: 11/09/2020, revisión: 04/03/2021, aceptación: 29/03/2021, publicación: septiembre de 2021

https://revistas.uasb.edu.ec/index.php/uru

(ID) Walter Fontana

wfontana1@yahoo.com

Universidad de la Defensa (Buenos Aires, Argentina)

https://orcid.org/0000-0002-7280-9103

DOI https://doi.org/10.32719/26312514.2021.4.3

\section{Resumen}

El actual proceso de globalización hace de la información un recurso que va más allá de su empleo por un Estado soberano y se extiende a otros grupos hegemónicos. Así, la información se vuelve no solo un bien de cambio, sino también una amenaza institucional cuando hay un manejo indebido de ella. La línea de análisis del trabajo es "Periodismo y desinformación", y su objetivo es mostrar las características de la desinformación en la era de la posverdad y presentar las categorías de este fenómeno comunicacional.

La presente investigación desarrolla la desinformación desde la comunicación social a partir de la actual situación de pandemia a nivel mundial, para lo cual hace referencia al trabajo desarrollado por el International Center for Journalists (ICFJ) como parte del ICFJ Global Health Crisis Reporting Forum, llevado a cabo en los primeros meses de 2020.

La desinformación es abordada desde los siguientes aspectos teóricos: la comunicación política y la construcción de la noticia. Desde la comunicación política se tiene en cuenta a los actores y su constante conflicto por la imposición de la agenda política en el espacio público mediatizado. Por otro lado, en la construcción de la noticia no solo se consideran los aspectos locales sino también la noticia transnacional, los medios digitales y las redes sociales. Lo más destacado es la importancia de los medios de comunicación como principales actores y responsables de la desinformación como proceso.

\section{Abstract}

The current globalization process makes information a resource that goes beyond its use by a sovereign state and extends to other hegemonic groups. This makes information not only a commodity for exchange, but also an institutional threat when there is improper handling of it. 
The subject of the work is "Journalism and Disinformation" and its objective is to show the characteristics of disinformation in the context of the Post-Truth Era and present the categories of this communication phenomenon.

This research develops disinformation from social communication based on the current situation of pandemic worldwide, for which to refer to the work developed by the International Center for Journalists (ICFJ) as part of the ICFJ Global Health Crisis Reporting Forum in the first months of 2020.

Disinformation is approached from the following theoretical aspects: Political Communication and Construction of the News. The Political Communication takes into account the actors of this and their constant conflict over the imposition of the political agenda in the mediated public space.

On the other hand, in the Construction of the News, not only local aspects are considered, but also transnational news, digital media and social networks.

The most prominent is the importance of the media as the main actor and responsible for disinformation as a process.

\section{Palabras clave $\cdot$ Keywords}

Desinformación, comunicación política, noticia, mentira, agenda, redes sociales, verosímil.

Disinformation, political communication, news, lie, agenda, social networks, plausible.

La manifestación de amenazas globales, como los conflictos armados en su amplia naturaleza, el terrorismo, los desastres naturales y actualmente las pandemias, hacen de las comunicaciones un recurso no solo de los Estados sino de todo grupo de poder. En esta situación de globalización, los procesos de aceleración en la transmisión de datos y de asimetría en los desarrollos científicos, así como los crecientes límites al acceso a una educación competitiva para un mercado laboral cada vez más tecnificado —en especial en países con problemas económicos-, hacen de la información un bien de cambio y, además, un recurso para sacar ventajas competitivas. El uso de la información como instrumento de agresión o arbitrio de dominación trae consigo la necesidad de modificar el mensaje en función de objetivos concretos de alguna de las partes en conflicto.

El tema de este trabajo es "Periodismo y desinformación", y se enmarca en la teoría de la comunicación. Su objetivo es determinar la dimensión de la desinformación —como fenómeno comunicacional - en el contexto actual, enmarcado en una situación de pandemia a nivel mundial.

Para empezar a delinear el fenómeno, este estudio comienza definiendo cómo la desinformación se hace presente en los medios con los primeros casos del COVID-19 en Latinoamérica, para luego desarrollar los aspectos teóricos. Una vez descrito el contexto mediático latinoamericano en que se manifiesta la desinformación, el próximo paso es definir las herramientas utilizadas en este proceso comunicacional destinado al engaño de la 
sociedad: en primer lugar, definir a los actores de la comunicación política en su lucha por imponer la agenda a la ciudadanía; en segundo término, determinar los aspectos teóricos referidos a la construcción de la noticia como principal vehículo desinformativo presente en los medios de comunicación tradicionales y aquellos aspectos que hacen a la noticia en las redes sociales; y, por último, definir qué se entiende por desinformación en el contexto teórico previamente expuesto, y determinar una categorización para precisar el modo en que este fenómeno se manifiesta en la sociedad contemporánea.

\section{La desinformación sobre el COVID-19 en Latinoamérica}

Muchos trabajos hacen referencia a la desinformación en el contexto actual, entre ellos el desarrollado por el International Center for Journalists (ICFJ) como parte del ICFJ Global Health Crisis Reporting Forum, llevado a cabo en los primeros meses de 2020. Tomando conciencia de la situación, la Organización Mundial de la Salud (OMS) definió al fenómeno como una infodemia, una pandemia en la que lo que se difunde no es una enfermedad, sino noticias falsas o maliciosas que aumentan el pánico y la angustia (Vales 2020).

La red Latam Chequea, creada en 2014 para reunir a las organizaciones de la región que se dedican a la verificación de datos, pudo identificar cuatro tipos de desinformación en redes sociales y otras plataformas digitales. Estas categorías -que, según se pudo comprobar, no son propias de la región, sino que coinciden con las que aparecieron en Europa y en Estados Unidos durante la expansión de la enfermedad-pueden ayudar a los medios a encarar el chequeo de estos contenidos.

Las cuatro categorías presentadas en el foro de ICFJ son las siguientes:

- Teorías conspirativas sobre el origen presunto del virus.

- Formas de contagio y expansión del virus (se difundieron falsas interpretaciones de estudios científicos).

- Supuestas curas o tratamientos (según la OMS, no hay terapias efectivas probadas ni vacuna salvadora por el momento). ${ }^{1}$

- Falsas medidas o alcances distintos a los dispuestos por los Gobiernos: falsos decretos, comparación de la situación en distintos países sin brindar contexto, y medidas sociales erróneas.

Según detalla el informe, las organizaciones comprobaron que en algunos casos estos mensajes buscaban robar datos personales, pero en otras situaciones la intención era simplemente generar falsas expectativas a gente que no estaba pasando un buen momento debido a la crisis.

${ }^{1}$ Recordemos que se hace referencia al primer semestre de 2020. 
A continuación se desarrollan los aspectos teóricos a fin de aclarar el contexto sobre el que se manifiesta la desinformación.

\section{Los actores de la comunicación política y la agenda social}

La desinformación no es un hecho de generación espontánea. Por ello, esta parte del trabajo no va a detallar el proceso de desinformación, sino que presentará, mediante el contexto teórico de la comunicación política, a quienes participan en la construcción de los mensajes, en qué ámbito esos mensajes son exhibidos a la sociedad, qué características asumen - considerando que los medios, incluido internet, son la principal plataforma para su difusión $-\mathrm{y}$, por último, de dónde surgen los temas que interesan a la sociedad y que sirven al fin último del engaño.

Para entender la comunicación política hay que hablar de una triangulación entre los únicos actores autorizados para hablar sobre política: los medios, la ciudadanía y el poder político - representado por los sectores hegemónicos-, en una constante lucha por la imposición de los intereses traducidos en la supremacía. Estos actores existen en una situación de complementariedad: el político va a la acción para convencer a la ciudadanía, los periodistas informan a la sociedad sobre los políticos, y la ciudadanía, a través de los medios, evalúa la acción de los políticos por medio de encuestas de opinión (Wolton 1989).

Lo común en esta complementariedad es que cada actor tiene un discurso con el que trata de imponer sus argumentos para dominar la agenda social: por un lado los políticos, por otro los periodistas, y por otro la sociedad. De esta manera, en la imposición de la agenda en la sociedad se da una dinámica que no es permanente, sino que asume contenidos distintos según sean tiempos de crisis, de vida normal o de elecciones (Wolton 1998). El constante enfrentamiento de discursos por parte de los actores evidencia la doble función de la comunicación política: por un lado, discutir los temas de interés para la sociedad y, por otro, eliminar aquellos que no interesan (Wolton 1989 y 1998; Gosselin 1995).

Aun cuando la innovación tecnológica en los medios haya modificado las reglas de ciertos hechos de interés social — como las campañas electorales, las situaciones de crisis y los conflictos internacionales-, la comunicación política se materializa en el espacio público y en él se enfrentan los discursos de los actores sociales. Pero desde la caída del acto público como espacio de la comunicación política ideal, actualmente el espacio público es de carácter simbólico. Se presenta ampliado por la irrupción de los medios de comunicación, ${ }^{2}$ lo que implica que se recurra a ellos para la difusión del discurso político y da origen a la mediatización del espacio público (Wolton 1995).

Hablar de la mediatización del espacio público implica reconocer en ello tres funciones básicas a cargo del medio de comunicación que interviene:

\footnotetext{
${ }^{2}$ En este caso hay que considerar, además de los medios tradicionales, la injerencia de internet y todo lo que ello implica en la construcción, la producción y la circulación de la noticia.
} 
- La transmisión del mensaje con la consiguiente selección y jerarquización de los temas de agenda. Esta forma de elección de los modelos de transmisión transforma el discurso político en acontecimiento.

- La puesta en escena a través de la elección de las citas, los cortes y el montaje del texto, que cambian la naturaleza del texto inicial.

- El comentario del discurso político por parte del periodista (Breton 1995).

Para Breton $(1995,363)$, el comentario mediático obedece a una doble tarea: por un lado, una tarea pedagógica, porque ayuda a comprender mejor lo que los grupos hegemónicos querían decir, y por otro lado, una tarea explicativa, situando al discurso en un contexto determinado y quitándole el significado que tenía en un comienzo. El paso que este autor describe es uno de los tantos momentos en que el proceso de desinformación se manifiesta en los medios.

De esta manera, el espacio público coincide con el espacio mediático, donde el segundo legitima todo lo que difunde el primero; es decir, todo lo mediatizado es legítimo y representativo del conjunto de los discursos (Bonilla Vélez 1997; Breton 1995; Wolton 1989). Así, todo discurso político fuera del espacio mediatizado es deslegitimado, y por lo tanto no válido para su discusión por los actores sociales. De ahí la importancia que cobra que toda acción desinformativa por parte de un actor de la comunicación política sea legitimada por los medios en sus múltiples formatos.

En esta lucha de poderes, los medios se transforman en los actores de mayor injerencia y capacidad de negociación. Son el espacio regulador de temas, mitos y consensos. En el siglo XXI, el espacio mediático es el lugar para la lucha por la legitimación de las acciones políticas, y en él la identidad juega un papel fundamental. Para los Estados con tradición republicana esta legitimación se da a través del consenso.

La sociedad mediatizada por el peso de los medios en la lucha por la hegemonía presenta la ilusión de una pluralidad de voces que se convierte en un artificio de la ciudadanía. Así, sin perder la dirección del sentido impuesto por el poder hegemónico, los medios logran neutralizar las posibles divergencias que pudieran aparecer frente a situaciones de crisis o conflicto. Su estrategia apunta a construir una ficción de que solo hay una mirada explicativa de la realidad (Luchessi y Bakmas 2007).

A partir de la violencia mediática, el poder hegemónico tiene la posibilidad de institucionalizar el temor y proporcionar mecanismos para el control social del discurso (Foucault 1986), los mismos que un Estado soberano activa para neutralizar la desinformación. Pero esa constante lucha por imponer la hegemonía no es otra cosa que la lucha por la imposición del relato, lo cual, visto desde la comunicación política, no es otra cosa que la lucha por la imposición de la agenda.

Por establecimiento de la agenda (agenda setting) se entiende al listado de temas que un medio jerarquiza como importantes y en cuya construcción operan tanto los criterios de noticiabilidad y el contrato de lectura como el peso de las fuentes y las agendas sociales (Martini 2000). 
La agenda mediática es la que construye un medio de comunicación determinado. La agenda pública o social la componen los temas o problemas con origen en la sociedad misma, en la mayoría de los casos, y también en sectores de opinión o actores sociales, casi siempre con un fuerte peso de publicidad y poder (Martini 1997; McCombs 2004).

El establecimiento de la agenda es un subproducto continuo y no buscado de la comunicación de masas. Se da en una vasta serie de escenarios geográficos de todo el mundo, e incluso en un amplio conjunto de agendas que van más allá de la comunicación política (McCombs 2004).

Este es un aspecto importante, considerando la injerencia que tienen las redes sociales en la presentación de la agenda a la sociedad, ya que permite la presencia en el espacio público mediatizado de otros agentes de influencia que burlan el control del relato de los sectores hegemónicos y contribuyen al proceso de desinformación en sus múltiples formas.

A continuación, el trabajo pasa a describir el principal vector por donde la desinformación se manifiesta — es decir, la noticia - y los aspectos que participan en ella.

\section{La construcción de la noticia en el contexto actual}

Al igual que en el apartado anterior, no se va a desarrollar específicamente el tema de la desinformación, sino aspectos teóricos que ayuden a entender su manifestación y principal agente - la noticia-, sus características — propias de cada ámbito- y la aparición de la noticia transnacional como manifestación de la comunicación global.

Un acontecimiento o hecho cualquiera puede transformarse en noticia siempre que sea de valor para un determinado público y que a criterio de un medio tenga la importancia suficiente. Bajo esta situación, una noticia es la construcción de una realidad presentada bajo el sentido de la organización mediática que la difundió. En ese contexto, Martínez Albertos la define así: "Noticia es un hecho verdadero, inédito o actual, de interés general, que se comunica a un público que puede considerarse masivo, una vez que ha sido recogido, interpretado y valorado por los sujetos promotores que controlan el medio utilizado para la difusión" (1977, 35-36).

Las características que hacen propia la construcción de la noticia parten de considerar tres aspectos: el contrato de lectura, ${ }^{3}$ la construcción de lo verosímil y los criterios de noticiabilidad.

Lo verosímil se constituye, según Stella Martini (1997), en la complejidad del cruce entre la opinión pública ${ }^{4}$ las representaciones sociales ${ }^{5}$ que se dan en sectores de la so-

\footnotetext{
${ }^{3}$ En lo referente al contrato de lectura, Martini (1997) dice que asegura un lazo en el tiempo entre el medio y el receptor.

${ }^{4}$ La opinión pública no es algo que sale del común de la ciudadanía. Actualmente, es algo fragmentado constituido por el conjunto de opiniones particulares regidas por intereses y, como consecuencia de esto, muchas veces en conflicto unas con otras. Si se las considera una producción emergente, su lugar de desarrollo es el espacio público, donde participan actores y espectadores para la construcción de la opinión a través del discurso público (Fontana 2017, 205).

${ }^{5}$ Para Irene Vasilaschis (1997), las representaciones sociales son las construcciones simbólicas individuales o colectivas a las que los sujetos apelan o que crean para interpretar el mundo, para reflexionar sobre su propia situación y la de los demás, y para determinar el alcance y la posibilidad de su acción histórica.
} 
ciedad con características propias. De ahí la importancia dada a la construcción de la noticia que privilegia el estilo narrativo/argumentativo por sobre el informativo y, con ello, la prevalencia de la subjetividad. Lo verosímil se vincula con el efecto de identificación del medio, porque este presenta la noticia como el lector quiere; este fenómeno conecta cada noticia con otras leídas, a la manera de una trama que las hace verosímiles.

Los criterios de noticiabilidad tienen su anclaje en la cultura de una sociedad; se relacionan con sus sistemas clasificatorios y las agendas temáticas habituales de los medios, en íntima correspondencia con su política editorial. La noticiabilidad de un acontecimiento posee una red de entramados materializada en una negociación al momento de su génesis, que para Eliseo Verón (1995) y Jean Mouchon (1999) tiene que ver con una relación entre medios y sectores hegemónicos de la sociedad. Danny Schechter dice:

Vivimos en una época de políticas mediáticas, gobernados no solamente por políticos, sino por lo que resulta ser una mediocracia, o sea una relación de mutua dependencia entre los medios y los políticos, un nexo de poder en que los líderes políticos utilizan la difusión mediática para formar opinión e impulsar políticas. $(2004,38)$

De los tres aspectos arriba mencionados, propios de la construcción de la noticia, el concepto de verosimilitud es el más importante en la desinformación, porque el público al cual esta va dirigida no solo debe considerar que la información es de su interés y que responda a los parámetros de verdad e importancia según la agenda pública, sino que también debe responder a la identidad con el medio empleado por el agente malicioso. Por otro lado, la relación entre medios de comunicación y política descrita por Schechter sirve, además de al proceso de desinformación - a los efectos de mantener el discurso hegemónico-, como un recurso para defenderse de este.

La aparición de internet dio origen a los medios digitales y, al mismo tiempo, a un nuevo consumo a través de redes sociales como Facebook, Snapchat, Instagram, Twitter y otras. Estas apariciones crean una nueva forma de construir la noticia y de ver la realidad, alternativa a los medios tradicionales.

Los especialistas hablan de efecto burbuja o cámara de eco para hacer referencia a cómo en muchos casos las redes sociales devuelven la imagen del mundo que el perceptor quiere ver, aunque esté totalmente distorsionada de la realidad y la única voz escuchada sea la propia, ya que esa audiencia se rodea de otros que piensan como ella (Balmaceda 2018).

Ese pensamiento único, presente en las recepciones en busca de datos que apoyen ideas o hipótesis dispuestas previamente, responde según Tomás Balmaceda (2018) a un fenómeno llamado sesgo de confirmación, y deja a esos sectores disponibles a la manipulación de la información.

Las redes sociales y su horizontalidad permiten que cualquier usuario conectado a ellas esté en capacidad de opinar y de difundir sus ideas en forma instantánea a millones 
de personas. De esta forma se potencia el efecto burbuja y la segmentación de la información con datos no verificados.

El efecto burbuja, el sesgo de confirmación y la horizontalidad de acceso hacen de las redes sociales un recurso efectivo de la desinformación para la producción, la circulación y la generación de sentido de información por parte de cualquier actor que quiera construir una realidad alternativa.

Para Lila Luchessi (2007), hay un quiebre en los modos de producción de la noticia sustentado en cambios culturales que introducen tecnologías infocomunicacionales en la cotidianeidad de las audiencias, poniendo en crisis la actividad periodística y la información en segundo plano. Donde antes había un editor en la construcción de la noticia, las redes sociales incorporan un algoritmo que tiene en cuenta los consumos de la audiencia. La misma autora explica que el uso de redes sociales y algoritmos elimina la mediación de las empresas informativas. Las fuentes (públicas, privadas, personales, empresas, instituciones) acceden de forma directa, sin restricciones, a las audiencias.

Pero contrariamente a lo que se piensa, estas nuevas formas de circulación de la información generan muchos canales y poca información (Luchessi y Bakmas 2007). Son usinas que crean temas, posición en que son multiplicadas por usuarios que comparten y agregan información (Luchessi 2007).

A diferencia de los medios tradicionales, los de producción digital no interactúan con las audiencias, sino que se limitan a la observación de disensos y conflictos y a la censura de opiniones que estén fuera de los términos permitidos. Pero estas se alejan de las formas de consumo informativo y se acercan a las de toma de posición respecto a un tema $o$ asunto.

De este modo, los consumos en los medios digitales apuntan a reforzar lo que ya se sabe, se cree o se piensa. Se produce una dispersión informativa sostenida en comunidades de noticias convencidas de supuestos o creencias que no requieren chequeos. Desde esa óptica, el canal digital deja la acción de informar para pasar a legitimar posiciones de diferente tipo, sean políticas, religiosas, sociales, etc. Es esa legitimación lo que permite generar nuevos temas de agenda, y a su vez una nueva forma de contrato de lectura.

Lo que se plantea en los nuevos sistemas de producción y circulación de información es de una complejidad tal, que no permite concluir rápidamente quién produce los contenidos o cuánto de la agenda mediática es decidido por la fuente, por el propietario del medio, el editor o el periodista (Amado 2016).

El consumo de noticias desde las redes sociales es un hecho que va aumentando a medida que se renuevan las generaciones. Las redes sociales son un recurso que facilita la desinformación no solo por dificultar la exactitud del mensaje, sino por generar nuevos temas para la agenda social y mimetizar el origen de la fuente. Queda en pie la importancia de los medios tradicionales para ordenar la confianza en la audiencia frente a la duda del origen de la información generada en internet. 
Por otra parte, en aquellas crisis o situaciones de conflicto que trascienden las fronteras, y en las que participan actores más allá de los Estados, la situación comunicacional presenta una nueva esfera pública global de la cual una cultura cosmopolita puede nutrirse a través de medios de comunicación de alcance mundial capaces de desplazar a las culturas mediáticas cerradas en sí mismas y abrir nuevas posibilidades políticas (Fontana 2017, 12).

Este tipo de información de incidencia global, que se da en llamar noticia transnacional, suele llegar de agencias de noticias, organismos cargados de legitimidad y convertidos en fuentes de información presuntamente objetivas, cuya misión es la normalización del sentido. La noticia transnacional es una manifestación de la globalización de la información y un recurso del poder hegemónico transnacional para reforzar la naturalización del sentido de asuntos que son de interés para su agenda. En ese contexto, la desinformación nuevamente se puede manifestar en los medios tradicionales.

Desde esta perspectiva, las construcciones discursivas generadas se transforman en macrorrelatos que explican a grandes sectores de la sociedad la operatoria que lleva a plantear la criminalización de los disensos (Martini 2007), en especial en situaciones de crisis en las que los cursos políticos de acción necesitan del apoyo de la ciudadanía. En sociedades con bajo nivel institucional, ${ }^{6}$ los medios tradicionales constituyen, sin duda, un filtro natural de las noticias falsas, producto de su alto nivel de confianza con la ciudadanía.

A continuación, y sobre la base de los aspectos teóricos presentados, se pasan a desarrollar los conceptos centrales de la desinformación y sus alcances.

\section{Qué se puede entender por desinformación}

El presente trabajo deja de lado la perspectiva de lo que en Occidente se considera la guerra de la información o lo que en Rusia llaman medidas activas, para profundizar en el concepto de desinformación - central para la investigación - como fenómeno comunicacional en el actual contexto de producción y circulación de la noticia a través de los actores de la comunicación política (Fontana 2018).

De hecho, la desinformación existe desde tiempos inmemoriales, solo que en la situación actual se incorporan los medios de comunicación y actores hegemónicos a nivel global, y la producción y circulación de información en documentos, sonido e imagen ocurre en tiempo real. Pero esta incorporación de nuevos actores con capacidad de producción de sentido que inciden en la finalidad de la desinformación va más allá de la dominación; las redes sociales agregan al ciudadano común en la producción, circulación y

${ }^{6}$ Con este término se puede caracterizar no solo a muchas regiones del continente, sino también a otros sectores que no gozan de gobiernos de consenso. 
generación de sentido del discurso mediático. Surgen finalidades coyunturales y actores secundarios oportunistas apoyados por sectores hegemónicos, con lo que aparecen ventajas de rédito político/económico ajenas a los intereses nacionales.

Un ejemplo de lo arriba enunciado es la denuncia, un nuevo tipo de desinformación para referirse a cómo los propios medios de comunicación, en especial las grandes corporaciones, han abandonado su vertiente informativa y se han convertido en poderosos medios de influencia social en función de unos determinados intereses económicos o ideológicos, casi siempre en beneficio de las clases dominantes (Rodríguez Andrés 2018, 238).

Se puede afirmar que la esencia de la desinformación no tiene sentido positivo (resaltar las virtudes del emisor) sino negativo (desprestigiar al que se opone a sus intereses), sabiendo en todo caso que ese desprestigio resulta al final beneficioso para quien hace circular la desinformación.

Si se integra todo lo hasta aquí desarrollado en cuanto a aquellos a quienes se considera como actores de la comunicación política, a la construcción de la noticia en los medios tradicionales y a su producción y circulación en las redes sociales, según Martínez Musiño (2011) la desinformación presenta características propias, que pueden rastrearse en los orígenes mismos del concepto a inicios del siglo XX. Sirven como guía, además, para precisar la naturaleza de este fenómeno, tanto si se aplica en el ámbito de la comunicación social, de los conflictos, la política y las relaciones internacionales, como en otros campos:

- En primer lugar, se trata de un fenómeno intencional y manipulador de la información. No puede hablarse de desinformación si la fuente no tiene intención de engañar a sus receptores. Pero esa intención, como en cualquier otro tipo de manipulación informativa, permanece oculta, sin que los receptores lleguen a ser conscientes de que están siendo influidos. Y por eso resulta propio de la desinformación el hecho de ser una comunicación no atribuida a una determinada fuente $o$ atribuida a fuentes falsas.

- Su esencia comunicativa radica en la difusión de información engañosa y, por tanto, en el empleo de la mentira. Si bien hoy día se utiliza el término desinformación cuando se recurre a cualquier tipo de mentira, la esencia del fenómeno está vinculada no tanto al silencio o a la ocultación de datos como a las mentiras por comisión, es decir, a la difusión intencionada de información falsa. Se puede mentir por comisión, es decir, transmitiendo un hecho falso a sabiendas de que lo es y sin advertir su falsedad, y también por omisión, ocultando o silenciando datos relevantes sin los cuales es imposible el conocimiento completo de la verdad (Desantes-Guanter 1976; Soria 1997). Partiendo de esta clasificación básica, Durandin (1983 y 1995) ha diferenciado entre supresión (hacer creer que no existe una cosa que sí existe), adición (hacer creer cosas que en verdad no son 
reales, inventando una realidad paralela) y deformación (alterar la naturaleza de las cosas, bien de forma cuantitativa o cualitativa).

La distinción entre mentira por comisión o por omisión en la desinformación ha quedado sistematizada de forma muy clara por Sartori (1998), para quien hay que diferenciar entre subinformación, cuando se da información insuficiente, y desinformación, cuando se proporciona información distorsionada. Por ende, hablar de desinformación implica el empleo de mecanismos desinformativos, es decir, de técnicas oportunas que crean desinformación: por ejemplo, omitir datos importantes, difundir noticias que distraigan la atención, armar mensajes a partir de prejuicios sociales, difundir rumores cargados de tensión social y sin garantía de verdad, y manejar imágenes para manipular al público (Rodríguez Andrés 2018, 236).

- En tercer lugar, la fuente de desinformación busca que sus engaños sean difundidos por los medios de comunicación, que se convierten así, de forma casi siempre involuntaria, en el vehículo o soporte para propagar su mensaje. La desinformación, por tanto, está íntimamente ligada a los medios y al periodismo, puesto que es a ellos a quienes los mensajes deben engañar en primer lugar para conseguir difusión y alcanzar a la audiencia deseada. Tal como se aclaró, entre los actores de la comunicación política, en la lucha de poderes, los medios se transforman en los participantes de mayor injerencia y capacidad de negociación (Rodríguez Andrés 2018, 237-8).

- En íntima relación con el segundo y tercer atributos, tal como se aclara en el apartado de la construcción de la noticia, lo importante en la producción y circulación de la información no es que sea verdadera, sino verosímil. El consumo mediático actualmente tiene identidad etaria, ${ }^{7}$ en íntima relación con el tipo de noticia que circula por las redes y sus atributos, y los medios tradicionales sirven para confirmar los datos circulantes.

- El fin último de este proceso es el desprestigio de aquel considerado contrario a los intereses de la fuente que origina la desinformación (enemigo, adversario o el nombre con que se lo quiera designar). Ello implica la necesidad de una planificación e incluso la creación de organismos específicos destinados a diseñar y ejecutar esta acción comunicacional. Esto, a su vez, involucra la determinación de formas de desinformación, la elección de los medios para su difusión y de las audiencias destinatarias, y el momento de su aplicación (Rodríguez Andrés 2018, 242).

- La materialización de la desinformación se da el momento en que el público reacciona de acuerdo al querer de la fuente que desinforma. Algunas veces lo que

${ }^{7}$ Es la identidad propia de los grupos que comparten la misma edad o que son parte de la misma generación. 
busca el emisor de desinformaciones es influenciar las opiniones o ideas de los destinatarios; otras, suscitar actitudes que muevan a la gente a apoyar o rechazar personas, hechos o situaciones sociales (Martínez Musiño 2011).

La desinformación es uno de los recursos más importantes del poder político para minar la resistencia de sus adversarios. De ahí que sea precisamente el poder político el máximo difusor de mensajes desinformativos.

Hasta lo desarrollado aquí se puede definir a la desinformación como una manifestación comunicacional que, gracias a la aparición de internet y a la acción de las redes sociales, es particular del siglo XXI y se caracteriza por "un hacer o un no hacer discursivo por el cual se intenta que el o los receptores no puedan construir una realidad a través de sucesos objetivos" (Romero Rodríguez 2013)

\section{Las categorías de la desinformación}

La aplicación de la desinformación se da no solo en el discurso sino también en la imagen. Bajo esta circunstancia se presenta la siguiente categorización, según la forma de representarse en los medios y las redes sociales:

\subsection{En relación al contenido y la presentación del texto}

Información falsa: En este caso la noticia es inventada. Su contenido es inexacto porque el acontecimiento no existió.

Información inexacta: El acontecimiento existió pero los interrogantes de la noticia se ven alterados. El quién, el qué, el cuándo, el dónde y el cómo no se condicen con los hechos reales.

Información incompleta: La información es exacta pero no se conoce por completo. También estaría definida por lo que Schiller $(1996,49)$ denomina privación de datos (data deprivation): la falta de información socialmente necesaria para que un ciudadano decida adecuadamente sus acciones económicas, sociales y políticas (Ford 2005).

Información ambigua: Esta forma de construcción de la noticia es una combinación de las anteriores y normalmente se presenta con el empleo de recursos lingüísticos conocidos como tropos. Estas herramientas, muy empleadas en el discurso político, alteran el significado de las expresiones, por lo que afectan el nivel semántico de la lengua, ya sea involucrando palabras completas (tropos de palabra), como es el caso de las metasenemas $^{8}$ - la metáfora, la metonimia y la sinécdoque-, u oraciones completas (tropos de pensamiento), como algunos metalogismos ${ }^{9}$-la ironía y la paradoja, por ejemplo-.

\footnotetext{
${ }^{8}$ Figuras retóricas en las que hay una alteración o reinterpretación del significado natural de una palabra o imagen.

${ }^{9}$ Figuras retóricas que corresponden a las figuras de pensamiento. En ellas se considera la noción de un orden lógico de presentación de los hechos.
} 
En todo caso, el cambio producido en el tropo es de significado (Beristáin 1995).

Sobreinformación: Es un mecanismo muy frecuente que consiste en suministrar una cantidad abundante de datos al lector, que sistemáticamente consigue desorientarlo. En la mayoría de los casos se suministran sin una necesaria contextualización, entremezclando lo importante con lo secundario e incluso haciendo hincapié en este segundo aspecto (Verde 2007).

Rumor: ${ }^{10}$ Se caracteriza porque introduce como noticia temas nuevos, sin ningún tipo de antecedentes o de hechos objetivos en los que basarse; normalmente son hipótesis no comprobadas. Según Allport y Postman, el rumor "es una proposición específica para ser creída, que pasa de persona a persona generalmente por vía oral, sin medios de prueba seguros para demostrarla" (en ES Ayuntamiento de Getxo 2015, 10)

Sus principales características son las siguientes (StuDocu 2019):

- Se compone de mensajes difícilmente comprobables pero verosímiles.

- Es corto, sencillo e importante.

- Coincide con las tradiciones e intereses del público al que va dirigido el mensaje.

- La temática son los líderes, los colaboradores o hechos ocurridos en una institución de interés o a la que puede afectar.

- Expresa anhelos y ansiedades de un determinado público objetivo: necesidades, deseos, emociones, preocupaciones o miedos.

- La fuente normalmente se desconoce o se atribuye a alguien importante.

Allport y Postman identificaron dos factores principales que determinan la intensidad de un rumor: la importancia y la ambigüedad (en ES Ayuntamiento de Getxo 2015). El rumor tiene tendencia a la generalización. Cuando corresponde al estado de ánimo de una sociedad, se enriquecerá a medida que circule con aportes personales que le darán una cierta credibilidad, como la referencia a una fuente inexistente pero que alguno habrá añadido; de esta manera se produce su amplificación automática (Verde 2007).

\subsection{En relación al origen de la información}

Fuente de origen: La fuente de donde proviene la información es falsa o inexacta, y en algunos casos se desconoce. Cuando su origen es dudoso, se dice que la información proviene de una fuente gris; cuando es falsa, de una fuente negra. La información, en todo caso, no puede ser testeada.

\footnotetext{
${ }^{10} \mathrm{~A}$ pesar que es un fenómeno comunicacional que se considera muy particular, en íntima relación con los estereotipos y los prejuicios, y que requiere un desarrollo particular, en esta parte del trabajo no se lo puede dejar de considerar como un elemento más de la desinformación, razón por la cual se destacan los aspectos más importantes en relación con el tema en cuestión.
} 


\subsection{En relación a un hecho manifiesto}

Pseudoacontecimiento: Es un aconteciendo creado en forma ficticia mediante la teatralización de un hecho. El evento en sí es provocado, no existe en forma real. La intención es convertirlo en noticia para que sea difundido a través de los medios. Según Boorstin (1992), presenta los siguientes atributos:

- No es espontáneo, sino que aparece porque alguien lo ha inventado o planteado en los medios de comunicación.

- Se siembra principalmente con el propósito inmediato de ser reportado o reproducido. Lo importante es que sea de interés para el público al que va dirigido.

- Su relación con la realidad es ambigua. Normalmente hay interrogantes de la noticia que no son claros.

- Por lo general, se pretende que sea una profecía autocumplida. Lo más común es un ataque terrorista o el acto violento de algo o alguien que no lo es. El objetivo de los pseudoacontecimientos políticos es que parezcan actos auténticos y espontáneos. En las palabras de Jean Baudrillard (1991), los pseudoacontecimientos son una simulación de la realidad.

Esta clasificación contempla a la desinformación no solo desde el punto de vista del contenido de la información, sino desde el origen de la fuente, la circulación y su intencionalidad. Asimismo, el rumor como categoría se aplica a otras formas de la acción comunicacional. Con esta descripción se intentan plantear todas las formas en que la desinformación puede analizarse y comprenderse.

\section{Consideraciones finales}

Con el paso de los años, el concepto de desinformación ha empezado progresivamente a vincularse no solo a las intenciones del emisor, sino también a la perspectiva del destinatario o de los resultados de la acción. El término, como en sus orígenes, se usa cuando un actor hegemónico intenta ocultar o manipular la información, pero hoy se lo utiliza asimismo cuando se habla en forma genérica de falta de información de los ciudadanos sobre determinados asuntos, del conocimiento erróneo, sea cual sea el motivo y aun cuando no haya una intención por parte de alguien por mantenerlos engañados (Rodríguez Andrés 2018, 235).

Con el advenimiento de las redes sociales, todo actor que acceda al espacio público mediatizado llega a los actores de la comunicación política - políticos, medios y ciudadanía-, y con ello está en capacidad de influir en la agenda pública de una sociedad. La desinformación es una herramienta al alcance de cualquier antagonista con la aptitud antes mencionada. 
Lo que hay que hacer es delimitar correctamente la naturaleza de la desinformación como un fenómeno comunicacional. Según Roberto Rodríguez Andrés (2018), tiene una intencionalidad (el engaño) por parte de quien la patrocina, los medios de comunicación son el vehículo y, por último, es una actividad planificada.

Las categorías presentadas no son más que la modernización de los procesos de desinformación que siempre han existido, en especial desde que se emplearon los medios de comunicación social en la Primera y Segunda Guerras Mundiales, en la Guerra Fría y en ambas Guerras del Golfo, por mencionar algunos conflictos. Pero con el advenimiento de las redes sociales, la producción y circulación de la noticia da un giro a la desinformación. Por un lado, aparecen nuevos actores, y ya no hace falta que haya un conflicto armado o un proceso electoral; por otro, el agente de la acción no necesariamente busca tomar el poder de un Estado o sector de la sociedad. Muchos fenómenos siguen siendo empleados como recurso de la desinformación, entre ellos el rumor.

Aunque la difusión del mensaje haya sido involuntaria, los medios de comunicación, como el actor más influyente en el juego de la comunicación política, no pueden substraerse de una responsabilidad implícita que deriva del hecho de difundir noticias sin haberlas contrastado previamente con otras fuentes de información.

Por último, tal como se indica al principio del trabajo, la intención es determinar la dimensión de la desinformación como fenómeno comunicacional en el contexto actual de una situación de pandemia a nivel mundial, y no sirve de mucho presentar ejemplos si no se comprende la teoría. Este fenómeno ha existido y en el futuro va a presentar nuevas facetas.

\section{Referencias}

Amado, Adriana. 2016. "Del newsroom al cloudroom: El periodista y los productores de información". En Desafíos del periodismo en la sociedad del conocimiento. Discusiones a partir del Tercer Seminario Brasil-Argentina de Pesquisa Em Jornalismo (Bapijor), editado por Lila Luchessi y Luciano Videla, 13-22. Viedma, AR: Universidad Nacional de Río Negro.

Balmaceda, Tomás. 2018. “Posverdad: ¿Ya no se puede creer en nada?”. Clarín. 7 de enero. https://bit.ly/3hSiceF.

Baudrillard, Jean. 1991. Simulacros y simulación. Lisboa: Relógio D’Água.

Beristáin, Helena. 1995. Diccionario de retórica y poética. México: Porrúa.

Bonilla Vélez, José L. 1997. “Crisis de lo público y medios de comunicación: Información, paz y democracia en Colombia”. En Periodistas: Entre el protagonismo y el riesgo, compilado por Alicia Entel, 59-74. Buenos Aires: Paidós.

Boorstin, Daniel. 1992. The Image: A Guide to Pseudo Events in America. Nueva York: Vintage Bo. 
Breton, Philippe. 1995. "Medios, mediación y democracia”. En Comunicación y política, editado por Gilles Gauthier, André Gosselin y Jean Mouchon, 356-71. Barcelona: Gedisa.

Desantes-Guanter, José María. 1976. La verdad en la información. Valladolid, ES: Servicio de Publicaciones de la Diputación Provincial.

Durandin, Guy. 1983. La mentira en la propaganda política y en la publicidad. Barcelona: Paidós.

-. 1995. La información, la desinformación y la realidad. Barcelona: Paidós.

ES Ayuntamiento de Getxo. 2015. "Guía práctica para combatir los rumores y prejuicios sobre la diversidad cultural.” Ayuntamiento de Getxo. https://bit.ly/3vkpDPz.

Fontana, Walter. 2017. El discurso de EE. UU. y los diarios latinos. El caso nuclear iraní. Saarbrucken, DE: Editorial Académica Española.

—. 2018. "Mass media y conflictos híbridos: El caso de la guerra de la información y la Revolución de Color”. IOSR Journal of Humanities and Social Science 23 (3): 1-12. https://doi.org/10.9790/ 0837-2303070112.

Ford, Aníbal. 2005. Resto del mundo. Buenos Aires: Norma.

Foucault, Michael. 1986. El orden del discurso. París: Gallimard.

Gosselin, André. 1995. “Introducción”. En Comunicación y política, editado por Gilles Gouthier, André Gosselin y Jean Mouchon, 9-28. Barcelona: Gedisa.

Luchessi, Lila. 2007. "Juego de manos, juego de villanos. La mediatización de las fuentes en la construcción de la información". En Desafíos del periodismo en la sociedad del conocimiento. Discusiones a partir del Tercer Seminario Brasil-Argentina de Pesquisa Em Jornalismo (Bapijor), editado por Lila Luchessi y Luciano Videla, 62-3. Viedma, AR: Universidad Nacional de Río Negro.

—, y Gabriel C. Bakmas. 2007. "Punto ciego”. En Fronteras globales. Cultura, política y medios de comunicación, editado por Lila Luchessi y María Graciela Rodríguez, 251-73. Buenos Aires: La Crujía.

Martínez Albertos, J. L. 1977. El mensaje informativo. Barcelona: Asesoría Técnica de Ediciones.

Martínez Musiño, Celso. 2011. “Desinformar en la sociedad de la información”. Conferencia presentada en las Primeras Jornadas Virtuales Iberoamericanas de Ciencias de la Información y la Documentación, Buenos Aires, 10 al 30 de octubre.

Martini, Stella. 1997. "Periodismo en los 90: El trabajo sobre una nueva agenda pública”. En Periodistas: Entre el protagonismo y el riesgo, compilado por Alicia Entel, 147-62. Buenos Aires: Paidós.

-. 2000. Periodismo, noticias y noticiabilidad. Buenos Aires: Paidós.

-. 2007. "Agenda de la sociedad y agenda de los medios. Cuando lo transnacional atraviesa la vida cotidiana”. En Fronteras globales. Cultura, política y medios de comunicación, editado por Lila Luchessi y María Graciela Rodríguez, 113-41. Buenos Aires: La Crujía. 
McCombs, Maximiliam. 2004. Estableciendo la agenda. Buenos Aires: Paidós.

Mouchon, Jean. 1999. Política y medios. Barcelona: Gedisa.

Rodríguez Andrés, Roberto. 2018. "Fundamentos del concepto de desinformación como práctica manipuladora en la comunicación política y las relaciones internacionales". Historia y Comunicación Social 23 (1): 231-44. https://doi.org/10.5209/HICS.59843.

Romero Rodríguez, Luis. 2013. "Hacia un estado de la cuestión de las investigaciones sobre desinformación/misinformación”. Correspondencias \& Análisis 3: 319-42.

Sartori, G. 1998. Homo videns. Madrid: Taurus.

Schechter, Danny. 2004. Las noticias en tiempos de guerra. Barcelona: Paidós.

Schiller, Herbert. 1996. Information Inequality. The Deepening Social Crisis in America. Nueva York: Routledge.

Soria, Carlos. 1997. El laberinto informativo: Una salida ética. Pamplona, ES: Eunsa.

StuDocu. 2019. “Teoría y características del rumor”. StuDocu. https://bit.ly/34jLxGC.

Vales, Aldana. 2020. “Cuatro tipos de desinformación sobre el COVID-19”. International Center for Journalists. 22 de abril. https://bit.ly/3upNig7.

- 162 - Vasilaschis, Irene. 1997. Discurso politico y prensa escrita. La construcción de las representaciones sociales. Barcelona: Gedisa.

Verde, Orlegi. 2007. “La estrategia de la desinformación”. Primum Psicologicum. 16 de marzo. https://bit.ly/3bWdFDX.

Verón, Eliseo. 1995. “Mediatización de lo político”. En Comunicación y política, editado por Jean Gautier, André Gosselin y Jean Mouchon, 220-36. Barcelona: Paidós.

Wolton, Dominique. 1989. "Las contradicciones del espacio público". En El nuevo espacio público, editado por Jean Marc Ferry y Dominique Wolton, 110-30. Barcelona: Gedisa.

—. 1995. "Los medios, eslabón débil de la comunicación política”. En El nuevo espacio público, editado por Jean Marc Ferry y Dominique Wolton, 184. Barcelona: Gedisa.

—. 1998. "Pensar la comunicación. Introducción general: Existe un margen de maniobra”. Anuario 3. https://bit.ly/3fmMEM8. 